\title{
SHOT TO WIN: \\ ELECTORAL PROSPECTS AND REPUBLICANS' OPENNESS TO THE COVID-19 VACCINE
}

\author{
John V. Kane \\ New York University \\ jvk221@,nyu.edu \\ Ian G. Anson \\ University of Maryland, Baltimore County \\ iganson@umbc.edu
}

\begin{abstract}
The future of the COVID-19 pandemic in the United States will likely depend upon Americans' openness to vaccination against the virus. Yet a sizable partisan gap in perceptions of the vaccine has emerged. In this Letter, we propose that partisans' psychological aversion to electoral loss presents an opportunity for the deployment of framing messages to increase openness to the COVID-19 vaccine. Specifically, we analyze the effects of a "Shot to Win" (STW) message that frames vaccination as a means of ensuring that a party's members remain healthy enough to vote and defeat the opposing party. Results of a pre-registered survey experiment provide evidence that STW messaging increases Republicans' openness to vaccination across a variety of attitudinal and behavioral outcomes, and that STW's effectiveness extends beyond its function as a mere elite cue. More broadly, these results exemplify how out-party attitudes might be effectively leveraged in service of the public interest.
\end{abstract}

Word Count: 3942

Keywords: Vaccination; negative partisanship; electoral stakes; framing 
Public opposition to COVID-19 vaccination is a major concern in the contemporary United States, with serious implications for public health and the national economy (Charumilind et al. 2021). The ability of the U.S. to combat COVID-19 in the future depends upon the extent to which Americans express openness to COVID-19 vaccines and vaccine information-that is, whether they seek out accurate information about vaccines, elect to receive the vaccine, and continue to receive vaccine "booster shots" in subsequent years.

Despite the urgency of increasing public openness to COVID-19 vaccines, such attitudes currently exhibit a partisan political character. Though majorities of both partisan groups have been vaccinated, Democrats are more than 25 percentage points more likely to have been vaccinated than Republicans (Funk and Gramlich 2021), and Republicans have been less inclined to openly advocate for vaccination (Lerer 2021). Even among vaccinated adults, Republicans display relatively greater skepticism towards the vaccine's effectiveness, greater concern about its health risks, greater criticism of public pressure to vaccinate, and more positive sentiment toward individuals who choose to forego the vaccine (Tyson et al. 2021).

To close this partisan gap, recent research has explored various types of pro-vaccination messaging. Some effective messages have emphasized the personal and societal benefits of vaccination (Ashworth et al. 2021). Other research has more explicitly invoked the partisan nature of vaccine opposition, finding evidence that cues from partisan elites can be effective in increasing vaccine intentionality (Pink et al. 2021). Together, such studies demonstrate that while vaccine opposition is a relatively durable attitude, and that Republicans are disproportionately unsupportive of COVID-19 
vaccines, messaging that acknowledges the partisan nature of vaccine openness can boost public adherence to vaccination.

In this Letter, we build directly upon this research by attempting to further strengthen the efficacy of pro-vaccination messaging. Specifically, we draw upon political science literature documenting the rise in partisan polarization along affective and identity-based lines (Iyengar et al. 2019; Mason 2016). We propose pro-vaccination messaging that invokes interrelated components of Americans' partisan identities: antipathy toward members of the out-party (so-called "negative partisanship;" (Abramowitz and Webster 2018) and, relatedly, a strong emotional aversion to the prospect of losing elections to that out-party (Huddy, Mason, and Aarøe 2015). Results from these related literatures suggest that partisans may increase vaccine openness if the COVID-19 vaccine is framed as a means of protecting the in-party from electoral defeat to the out-party in upcoming national elections. With Republicans being disproportionately skeptical of vaccines and also disproportionately impacted by COVID-19 in terms of their physical health (Wood and Brumfiel 2021), this messaging is grounded in reality. That is, it is not unreasonable to suspect that asymmetric impact of the novel coronavirus across partisan lines could affect future electoral margins. Thus, messaging that warns of these potential electoral consequences should be capable of leveraging partisans' desire to defeat the opposing party and, in so doing, promote greater openness to the COVID-19 vaccine among American partisans.

We test this expectation empirically using a novel survey experiment $(n=1,217)$. Respondents to our survey were randomized into one of three experimental treatment groups. One group read a vignette that warned of the potential electoral consequences of remaining unvaccinated. We refer to this as our Shot to Win $(S T W)$ treatment. Cognizant that our $S T W$ treatment could implicitly function as an elite cue (see Pink et al. 2021), we included an explicit elite cue within the STW text, and randomly 
assigned a second group to read only this elite cue message $(E C)$. A third group received no persuasive message (Control). Crucially, this design enables us to statistically estimate the effect of $S T W$ relative to no persuasion, as well as the effect of $S T W$ net of its efficacy as a generic elite partisan cue.

The results of our experiment demonstrate that $S T W$ messaging consistently increases Republicans' openness towards vaccination. Specifically, invoking the threat of electoral loss improves Republicans' willingness to seek out information about vaccines, to persuade others to get vaccinated, and to pursue the vaccine themselves. While Democrats were also shown $S T W$ messaging (i.e., warning of potential electoral loss against Republicans if more Democrats did not get vaccinated), these partisans exhibited more modest, less directionally consistent effects, perhaps due to ceiling effects that resulted from high initial openness to vaccination. Nevertheless, together, the results provide substantial evidence that messaging invoking the threat of electoral loss can be deployed in service of goals which enhance public safety and the public good.

\section{BACKGROUND, THEORY, AND EXPECTATIONS}

Existing research documents the power of partisanship and partisan identity in driving attitudes and attitudinal shifts (e.g., Kinder and Kalmoe 2017). Like all social identities, a crucial component of partisan identity is that of feelings of animus toward members of a competing group -i.e., the out-party (Mason 2016; Van Bavel and Packer 2021). Indeed, much research documents how Americans have come to increasingly distrust and dislike members of the out-party (Hetherington and Rudolph 2015), and even exhibit disproportionate attentiveness to affect-laden messages from trusted partisan elites 
(Webster 2021). ${ }^{1}$ Thus, feelings of antipathy towards the out-party can underlie a variety of consequential behaviors. For example, recent evidence finds that partisans' willingness to share posts via social media stems from a desire to highlight negative stories about the out-party (e.g., Rathje et al. 2021).

A related element of partisan identity is that it also stands to raise the stakes of political events and, especially, political contests. In particular, partisans display a marked aversion to the prospect of electoral defeat (Huddy, Mason, and Aarøe 2015). While winning elections confers strong psychological affirmation to partisans on the winning side, electoral defeat elicits even stronger feelings of despair and unhappiness among partisans (Pierce et al. 2016).

We reason that this threat of electoral loss may not only exert a meaningful effect upon attitudes, but also potentially function as a strong incentive to engage in specific behaviors. Following this logic, we propose COVID-19 vaccine messaging that leverages the threat of electoral loss as a source of motivation for political partisans. This approach builds directly upon existing research, which has examined framing messages that invoke generic cues from co-partisan elites. In Pink et al.'s (2021) recent study, for example, such elite endorsements increased partisan vaccination intentions by $7 \%$ among Republicans and 5.7\% among Democrats. However, given the urgent nature of maximizing public openness to COVID-19 vaccination — both at present and throughout years to come - we seek to build upon these efforts by explicitly leveraging the prospect of electoral loss and, in particular, partisans' compelling desire to avoid it.

\footnotetext{
1 While scholarly definitions of "negative partisanship" differ, in this study we adhere to a definition which conforms to Lelkes' (2021) description of "partisan disdain," or negative affect towards the out-party.
} 
Invoking the threat of electoral loss thus reorients pro-vaccine messaging in a way that highlights partisan unity and strength in the face of a shared opponent-i.e., the out-party. We propose that, while appeals to increase openness to vaccination may, on their own, likely be met with skepticism by some partisans (perhaps especially Republicans), the pro-in-party (and anti-out-party) nature of framing vaccination as a strategy for avoiding electoral defeat stands to potentially counteract such resistance. We therefore aim to test the following hypothesis:

H1. Messaging designed to invoke partisan threat of electoral loss will increase partisans' openness towards COVID-19 vaccination.

In testing this hypothesis, we employ a broad, multi-faceted operationalization of "openness toward COVID-19 vaccination". Consistent with existing research (Pink et al. 2021), we measure partisans' intentions to receive the vaccine. However, it is increasingly clear that additional outcomese.g., public desire for factual information about a COVID-19 vaccine, knowledge of how and where to obtain the vaccine, intentions to receive a "booster shot," and willingness to encourage others to become vaccinated - will be crucial determinants of COVID-19's future trajectory in the United States. Our study, therefore, also builds upon existing research by employing a wider array of attitudinal and behavioral outcomes than has heretofore been the case.

\section{MATERIALS AND METHODS}

To investigate H1, we fielded a preregistered survey experiment via Lucid, from September 22-23 of 2021, that included quotas ensuring that the sample would be nationally representative with respect to race/ethnicity, age, gender, and geographic region. The final sample 
included 1,561 adults, 1,217 of which leaned or identified with either the Republican or Democratic Party. We selected these partisans for a resulting study $\mathrm{N}$ of $1,217.2$

Following informed consent, survey respondents first indicated their preferred political party and vaccination status. (Approximating national polling data, $60 \%$ of Republicans in our sample report having been vaccinated compared to $81 \%$ of Democrats.) Respondents were then randomized into one of three treatment conditions. Table 1 contains the full text of the experimental treatments below. One third of the sample of partisans was exposed to a Control condition, in which no vignette was presented to participants. Another third received an Elite Cue (EC) vignette (modeled after Pink et al. 2021), which contained a generic message from the Republican (Democratic) National Committee urging their respective co-partisans to seek vaccination. This cue condition also mentions Donald Trump (Joe Biden) in Republican (Democratic) conditions.

We test $\mathbf{H} 1$ by comparing the Control and $E C$ conditions to a third experimental condition, which we label Shot to Win (STW). In this condition, respondents read the same message from their respective national party committee contained in $E C$, before exposure to an additional series of paragraphs urging respondents to seek vaccination due to the electoral consequences of in-party members becoming sick. The treatment frames vaccination as consequential for the 2022 and 2024 elections, urging respondents to "get vaccinated, get protected, and... get out and WIN."

\footnotetext{
${ }^{2}$ Data, code, and other replication materials for the study will be made available on osf.io upon publication at [link redacted for review]. Our project involved human subjects research and was classified as Exempt by the [redacted] Institutional Review Board (Protocol \#2021-675). Informed consent was obtained through survey respondents' click-through acknowledgement after reading an informed consent script.
} 


\section{TABLE 1. Text Featured in Experimental Vignettes}

\begin{tabular}{|c|c|}
\hline Elite Cue (EC) Vignette Text & Shot to Win (STW) Vignette Text \\
\hline $\begin{array}{l}\text { A Message from the Republican National Committee } \\
\text { The Republican National Committee (RNC) often serves as } \\
\text { the national voice of the Republican party. The Republican } \\
\text { National Committee recently released the following } \\
\text { statement regarding COVID-19 and vaccines: } \\
\text { "We strongly agree with former President Trump and } \\
\text { members of his administration, who have gone on record by } \\
\text { encouraging all Americans to get the COVID-19 vaccine as } \\
\text { soon as possible to stop the spread of the virus. Thank you, } \\
\text { Donald Trump, for your leadership on this issue." }\end{array}$ & $\begin{array}{l}\text { A Message from the Republican National } \\
\text { Committee: Vaccines Will Help Our Party Win! } \\
\text { [The EC vignette text appeared here, in conjunction } \\
\text { with the message below] } \\
\text { "Based on our own research, if you don't get } \\
\text { vaccinated between now and the next election, you } \\
\text { have a much higher risk of getting very sick. This } \\
\text { means you might not be able to participate in the next } \\
\text { election to help our party win." } \\
\text { "Please make sure you and your friends/relatives get } \\
\text { vaccinated so you can help us defeat the Democrats } \\
\text { in the next election. The stakes are very high: If we } \\
\text { don't get vaccinated against COVID-19, Democrats } \\
\text { might keep their hold on Congress in the 2022 } \\
\text { midterm elections. They might possibly even keep the } \\
\text { White House in 2024." } \\
\text { "We just can't take that risk. The COVID-19 vaccine } \\
\text { is how we can keep Republicans healthy and strong. } \\
\text { So let's get vaccinated, let's get protected, and let's } \\
\text { get out and WIN in 2022 and 2024!" }\end{array}$ \\
\hline
\end{tabular}

Notes: Vignette text for EC and STW conditions.

Next, respondents were asked a variety of questions to gauge openness to COVID-19 vaccination. These measures included: (1) an opportunity be provided, at the close of the survey, with a link to factual vaccine information from the Centers for Disease Control and Prevention (CDC), as well as (2) a link to CDC guidance on where to obtain the vaccine; (3) respondents' self-reported likelihood of obtaining the vaccine (if unvaccinated) or, (4) a coronavirus booster shot (if already vaccinated) once they become available; and, (5) respondents' self-reported likelihood of encouraging vaccine-hesitant family members to get vaccinated. The first two outcomes are binary measures ("No" (0) or "Yes" (1)), while the remaining outcomes were measured on 5-point scales ranging from "Extremely unlikely" (1) to "Extremely likely" (5). All outcomes were then rescaled to range from 0 to 
1 to allow for easier interpretation and comparison. See the SI for additional information on question wording, study design, and preregistration.

Given the partisan nature of both COVID-19 vaccination and our experimental vignettes, treatment effects were assessed separately for Republicans and Democrats using logistic regression for binary outcomes and OLS for continuous outcomes. For each dependent variable, we present two experimental contrasts. First, we estimate the effects of STW versus Control to evaluate whether the full $S T W$ message can influence partisans' openness towards vaccines. To more directly evaluate H1, we next estimate the treatment effect of the $S T W$ condition relative to the generic $E C$ condition.

\section{RESULTS}

The results of our experiment consistently indicate that the Shot to Win (STW) condition is capable of increasing Republicans' openness towards COVID-19 vaccination. Figure 1 displays the effects of the $S T W$ treatment on Republican respondents. Within each panel of the Figure, we see the contrast of $S T W$ relative to the Control (top estimate) as well as to the $E C$ treatment (bottom estimate). For every dependent variable measured in the study, the estimated effect of $S T W$ framing relative to both the Control and EC conditions was positively signed, providing evidence in favor of H1. The top panels indicate that the $S T W$ treatment motivated Republicans to be substantially more likely to request factual CDC information about the vaccines. This effect was on the order of 18 percentage points versus Control and 14 percentage points versus $E C$ ( $p<.001$ and $p<.01$, respectively, using 1-tailed tests given our directional expectation). STW similarly increased Republicans' demand for CDC guidance on how 


\section{FIGURE 1. Effect of "Shot to Win" Framing on Republican Openness to COVID Vaccine}

Requests for CDC Vaccine Information

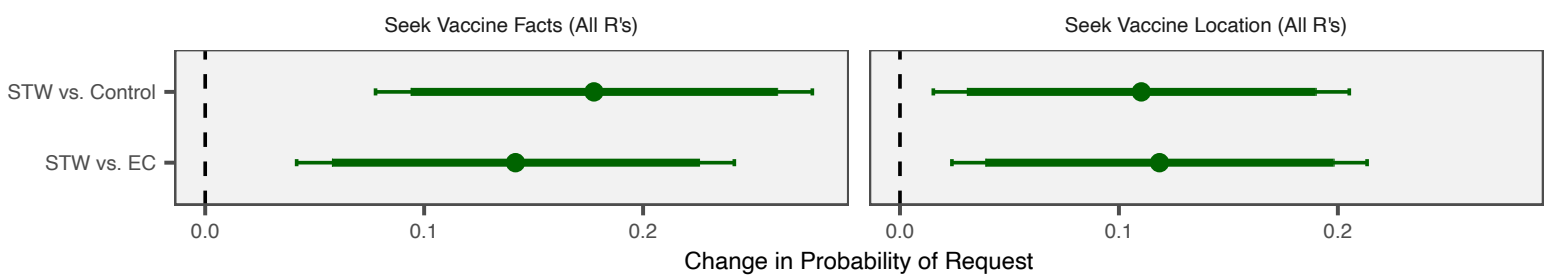

Intention to Vaccinate

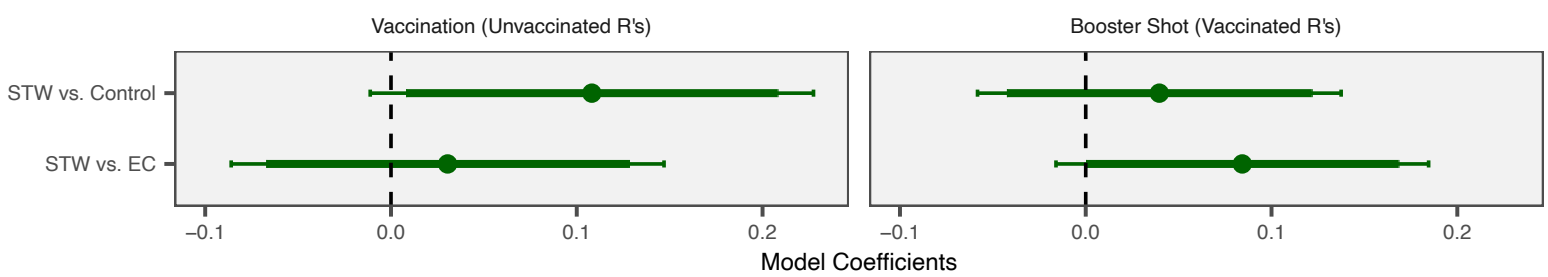

Willingness to Promote Vaccination

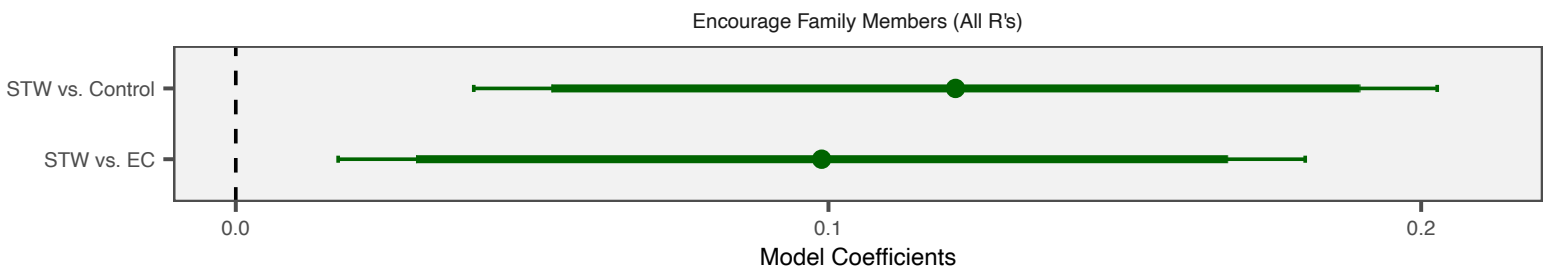

Notes: All outcomes range from 0 to 1 . Requests for CDC Vaccine Information outcomes (top row of figures) are based on logistic regression models; all other outcomes are OLS (significance tests were substantively identical when specifying ordered logistic regression models). Total number of Republicans/Republican leaners $=476$ (60\% of which were vaccinated). CIs are $90 \%$ (thick bars) and $95 \%$ (thin bars).

to locate a vaccine provider: the effect of $S T W$ was 11 percentage points versus Control and 12 percentage points vs. $E C$ ( $p<.001$ and $p<.05$, respectively).

The center-left panel of Figure 1 indicates that, relative to the Control, the $S T W$ message increases willingness to obtain the vaccine among unvaccinated Republicans by 11 percentage points $(p<.05)$. Relative to the $E C$ treatment, the estimated effect is again positive ( 3 percentage points) though not significant at conventional levels $(p=.30)$. The center-right panel indicates that, among vaccinated Republicans, the $S T W$ treatment also increases willingness to obtain a "booster" vaccine. $S T W$ framing resulted in an 8 percentage-point increase in booster vaccine willingness compared to the $E C$ treatment 
group $(p<0.05)$; a 4 percentage-point increase relative to the Control did not attain conventional significance $(p=0.21)$.

The bottom panel of Figure 1 demonstrates that $S T W$ increases Republican willingness to encourage vaccine-hesitant family members to get vaccinated. Relative to the Control, STW increases this willingness by 12 percentage points $(p<0.01)$. Similarly, the $S T W$ vs. $E C$ contrast in this case was 10 percentage points $(p<0.01)$. Because research shows that encouragement from family members can be a powerful influence for overcoming vaccine hesitancy (Kirzinger, Sparks, and Brodle 2021), this finding is especially notable insofar as it suggests that the efficacy of STW messaging can potentially extend beyond only those who directly received it.

Overall, then, the results for $S T W$ framing are, in each case, signed in a positive direction (indicating an increase in Republican openness to the COVID-19 vaccine), and typically significant at conventional levels regardless of whether Control or EC is specified as the baseline. Additional exploratory analyses found that, in general, the estimated effects of $S T W$ framing were not significantly moderated by respondents' geographic region (South vs. non-South) or partisan strength. A notable exception is for the booster shot outcome: whereas stronger Republican partisanship was associated with lower willingness to obtain the booster shot in the Control and EC conditions, it was associated with greater willingness in the $S T W$ condition, suggesting that the $S T W$ messaging resonated more strongly with stronger (versus weaker) Republican identifiers.

Figure 2 presents the results of $S T W$ vs. Control and $S T W$ vs. EC contrasts for Democrats. Perhaps owing to their already high openness to the COVID-19 vaccine, $S T W$ had weaker and less consistent effects relative to the $E C$ and Control conditions for Democratic respondents. Notably, Figure 2 shows that $S T W$ significantly increases Democrats' willingness to encourage family members to vaccinate (6 percentage points relative to either Control or $E C, p<0.05$ ). Again, while these findings 
FIGURE 2. Effect of "Shot to Win" Framing on Democratic Openness to COVID Vaccine
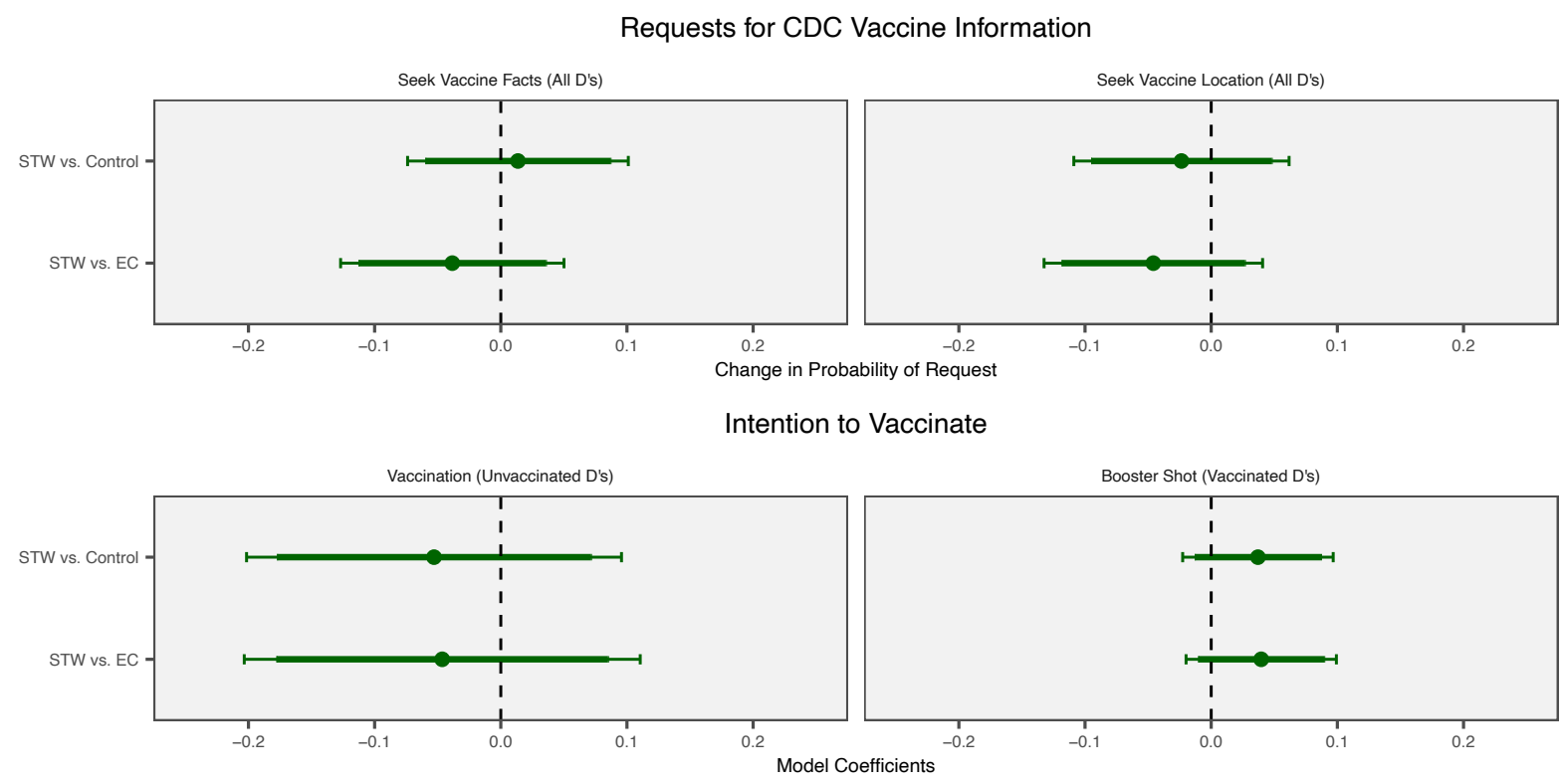

Willingness to Promote Vaccination

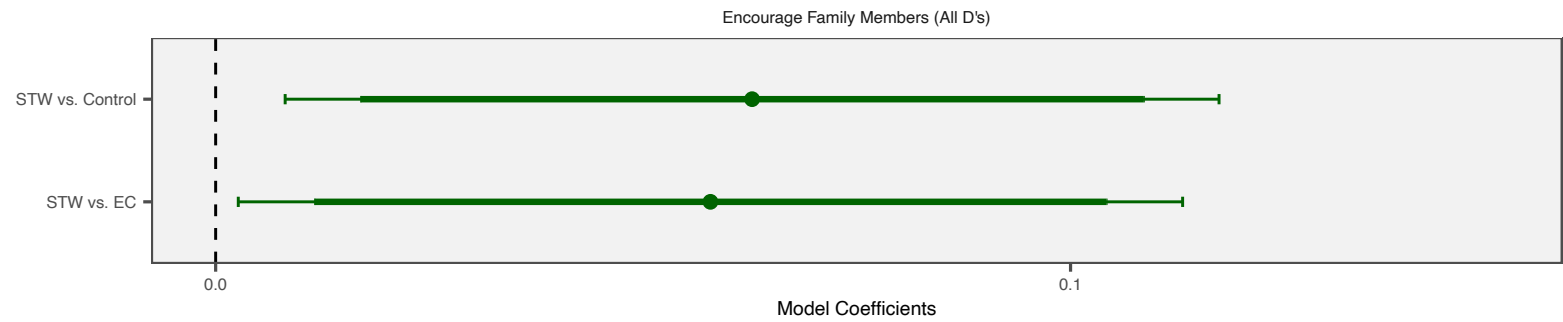

Notes: All outcomes range from 0 to 1 . Requests for CDC Vaccine Information outcomes (top row of figures) are based on logistic regression models; all other outcomes are OLS (significance tests were substantively identical when specifying ordered logistic regression models). Total number of Democrats/Democratic leaners $=81 \%$ of which were vaccinated). CIs are $90 \%$ (thick bars) and $95 \%$ (thin bars).

are less directly related to respondents' own willingness to become vaccinated, a willingness to promote the vaccine's effectiveness among close contacts is likely to have important social spillover effects. STW also (marginally) significantly increases willingness to obtain the booster shot (4 percentage points 
relative to $E C, p<0.10$ ) which, again, is a crucially important outcome to the extent that Americans will need repeated doses of the COVID-19 vaccine in years to come.

However, we see no positive treatment effect for $S T W$ on willingness to seek vaccine facts relative to $E C(\delta=-3.8$ percentage points, $p=0.39)$ nor on willingness to seek out a location where vaccines are available $(\delta=-4.5$ percentage points, $p=0.30)$. Additionally, we see no significant effects for $S T W$ relative to $E C$ among Democrats in terms of willingness to vaccinate (top left panel; $\delta=-4.6$ percentage points, $p=0.56$ ). However, this last result is likely influenced by the fact that just $18.9 \%$ of Democratic respondents report being unvaccinated, reducing the sample size for this analysis to just 140 participants.

As a final corroboration of $S T W$ framing's efficaciousness, post-outcome manipulation checks (Kane and Barabas 2019) confirmed that the $S T W$ treatment did indeed significantly increase both Republicans' and Democrats' perceptions that their party could lose the upcoming congressional and presidential elections (see SI for details). ${ }^{3}$

\section{DISCUSSION}

Several important implications emerge from our findings. First, our results suggest that, insofar as Republican elites grapple with the unpopularity of pro-vaccine messages among their constituents, the anti-out-party nature of $S T W$ framing could allow elected officials to openly advocate for vaccination while avoiding threats from anti-vaccination primary challengers who might otherwise accuse such

\footnotetext{
3 These checks also help to assuage the potential concern that Democrats witnessed smaller treatment effects (vis-à-vis Republicans) because they were less receptive to $S T W$ messaging. This furthers our suspicion that the more modest results observed for Democrats may be due to ceiling effects.
} 
appeals as being insufficiently loyal to the party. ${ }^{4}$ Thus, Republican public officials may be able to employ "Shot to Win" (STW) messaging to successfully encourage their Republican constituents to be more open to COVID-19 vaccines and vaccine information — an urgent public health priority, and one that will likely remain so for years to come given the likelihood that new variants of the virus continue to emerge. Helping facilitate vaccine promotion among Republican elites is vital for boosting Republican vaccination rates, as rank-and-file voters are increasingly attentive to co-partisan message senders (Broockman and Ryan 2016).

Second, the logic underlying the $S T W$ message may be applicable in other countries where strong partisan loyalties have caused partisan gaps in vaccination rates to emerge. Provided their elections remain competitive, elites could deploy similar messaging to potentially great effect. As vaccine availability increases worldwide, $S T W$ framing might be effectively employed in countries where partisan antipathy has previously yielded disagreement over basic scientific recommendations. For example, vaccination openness in India might be enhanced if Bharatiya Janata Party (BJP) officials advocated $S T W$ messaging rather than contributing to sectarian and anti-minority misinformation campaigns (Badrinathan 2021).

Third, and most broadly, our findings offer an example of how extant partisan divisions can be leveraged in the service of pro-social behavior. The present results specifically show that the threat of electoral loss is a powerful psychological tool for partisan communicators in that it is able to draw upon

\footnotetext{
${ }^{4}$ Recently, Republican members of the "Doctors Caucus" convened to stress the importance of the COVID-19 vaccine (Colvin and Slodysko 2021). However, these efforts have been controversial among anti-vaccine constituents, highlighting the need for in-party-resonant messaging beyond generic pro-vaccine cues.
} 
deep anxieties among rank-and-file adherents and, thus, spur them to consider behaviors that they might otherwise avoid. It is not currently well known how this type of messaging might feed back into partisans' antipathy towards each other, or their attitudes towards elections and democracy. Thus, we acknowledge that there are important ethical questions that naturally arise when employing such a strategy, and that such questions deserve further consideration and discussion in future work.

Nevertheless, we submit that messaging that leverages partisan antipathy may be useful to employ when conventional, non-partisan messaging no longer exerts a detectable influence on public attitudes, and when public outcomes require urgent solutions. Given the severity of the present pandemic and the need for the public to remain open to COVID-19 vaccination in the coming years, our results suggest that such an approach may be an appropriate and effective tool for party elites hoping to increase support for the vaccine among the party rank-and-file.

Much work remains to be done to explore the effectiveness of treatments designed to leverage partisanship in service of pro-social goals. So, too, should future work contend more fully with the downstream consequences of such interventions for partisan attitudes themselves. In a society in which extremist beliefs and behaviors are often reinforced by members of the partisan elite, invoking negative partisanship as a communications strategy may do little to defuse partisan divisiveness. However, the present study provides evidence that such messaging can be effectively deployed in the event of an urgent public health crisis that, like much else, has divided across partisan lines. 


\section{REFERENCES}

Abramowitz, Alan I. and Steven Webster. 2018. Negative Partisanship: Why Americans Dislike Parties But Behave Like Rabid Partisans. Political Psychology 39, 119-35.

Ashworth, Madison, Linda Thunström, Todd L. Cherry, Stephen C. Newbold, and David C. Finnoff. 2021. "Emphasize Personal Health Benefits to Boost COVID-19 Vaccination Rates." Proceedings of the National Academy of Sciences 118 (32). https:/www.pnas.org/content/118/32/e2108225118.

Badrinathan, Sumitra. 2021. "India is Facing an Epidemic of Misinformation Alongside COVID-19." The Washington Post. Available at

https://www.washingtonpost.com/opinions/2021/06/07/india-misinformation-covid-19-pandemic/. Deposited 7 June.

Broockman, David E., \& Ryan, T. J. 2016. Preaching to the choir: Americans prefer communicating to copartisan elected officials. American Journal of Political Science, 60(4), 1093-1107.

Charumilind, Sarun, Matt Craven, Jessica Lamb, Adam Sabow, Shubham Singhal, and Matt Wilson. 2021. "When Will the COVID-19 Pandemic End? | McKinsey." McKinsey \& Company. https://www.mckinsey.com/industries/healthcare-systems-and-services/our-insights/when-willthe-covid-19-pandemic-end.

Colvin, Jill, and Brian Slodysko. 2021. "In shift, GOP ramps up vaccine push as resistance hardens." Associated Press, July 23. https://apnews.com/article/joe-biden-health-government-and-politicscoronavirus-pandemic-0433cfa3b684b50d0c67ed254f8d8c39

Funk, Cary, and John Gramlich. 2021. "10 Facts about Americans and Coronavirus Vaccines." Pew Research Center (blog). September 20, 2021. https://www.pewresearch.org/facttank/2021/09/20/10-facts-about-americans-and-coronavirus-vaccines/.

Gerber, Alan S., \& Huber, Gregory A. 2009. Partisanship and economic behavior: Do partisan differences in economic forecasts predict real economic behavior? American Political Science Review, 103(3), 407-426.

Hetherington, Marc J., and Thomas J. Rudolph. 2015. Why Washington Won't Work: Polarization, Political Trust, and the Governing Crisis. Chicago: University Of Chicago Press.

Huddy, Leonie, Lilliana Mason, and Lene Aarøe. 2015. "Expressive Partisanship: Campaign Involvement, Political Emotion, and Partisan Identity.” American Political Science Review 109 (01): 1-17.

Iyengar, Shanto, Yphtach Lelkes, Matthew Levendusky, Neil Malhotra, and Sean J. Westwood. 2019. "The Origins and Consequences of Affective Polarization in the United States." Annual Review of Political Science 22 (1): 129-46.

Kane, John V., and Jason Barabas. 2019. "No Harm in Checking: Using Factual Manipulation Checks to Assess Attentiveness in Experiments.” American Journal of Political Science 63 (1): 23449. 
Kinder, Donald R., and Nathan P. Kalmoe. 2017. Neither Liberal nor Conservative: Ideological Innocence in the American Public. Chicago, IL: University of Chicago Press.

Kirzinger, Ashley, Grace Sparks, and Mollyann Brodle. 2021. "KFF COVID-19 Vaccine Monitor: In Their Own Words, Six Months Later." Kaiser Family Foundation: Kaiser Family Foundation. https://www.kff.org/coronavirus-covid-19/poll-finding/kff-covid-19-vaccine-monitor-in-theirown-words-six-months-later/.

Lelkes. 2021. What do we Mean by Negative Partisanship? The Forum 19 (3): doi: https://doi.org/10.1515/for-2021-2027.

Lerer, Lisa. 2021. "How Republican Vaccine Opposition Got to This Point." The New York Times, July 17, 2021, sec. U.S. https://www.nytimes.com/2021/07/17/us/politics/coronavirus-vaccinesrepublicans.html.

Mason, Lilliana. 2016. “A Cross-Cutting Calm How Social Sorting Drives Affective Polarization.” Public Opinion Quarterly 80 (S1): 351-77.

Pink, Sophia L., James Chu, James N. Druckman, David G. Rand, and Robb Willer. 2021. "Elite Party Cues Increase Vaccination Intentions among Republicans." Proceedings of the National Academy of Sciences 118 (32). https://www.pnas.org/content/118/32/e2106559118.

Pierce, L., Rogers, T., \& Snyder, J. A. 2016. Losing hurts: The happiness impact of partisan electoral loss. Journal of Experimental Political Science, 3(1), 44-59.

Tyson, Alec, Cary Funk, Brian Kennedy, and Courtney Johnson. 2021. "Majority in U.S. Says Public Health Benefits of COVID-19 Restrictions Worth the Costs, Even as Large Shares Also See Downsides." Pew Research Center Science \& Society (blog). September 15, 2021. https:/www.pewresearch.org/science/2021/09/15/majority-in-u-s-says-public-health-benefits-ofcovid-19-restrictions-worth-the-costs-even-as-large-shares-also-see-downsides/.

Rathje, S., Van Bavel, J.J. and Sander van der Linden. 2021. Out-group animosity drives engagement on social media, Proceedings of the National Academy of Sciences 118, 26.

Van Bavel, Jay J., and Dominic J. Packer. 2021. The Power of Us: Harnessing Our Shared Identities to Improve Performance, Increase Cooperation, and Promote Social Harmony. New York: Little, Brown Spark.

Webster, Steven W. 2021. The Role of Political Elites in Eliciting Mass-Level Political Anger. The Forum 19(3): doi: https://doi.org/10.1515/for-2021-0023.

Wood, Daniel, and Geoff Brumfiel. 2021. "Pro-Trump Counties Now Have Far Higher COVID Death Rates: Shots - Health News: NPR.” December 5, 2021. https://www.npr.org/sections/healthshots/2021/12/05/1059828993/data-vaccine-misinformation-trump-counties-covid-death-rate. 


\section{SUPPLEMENTARY INFORMATION}

\section{SHOT TO WIN: \\ ELECTORAL PROSPECTS AND REPUBLICANS' OPENNESS TO THE COVID-19 VACCINE}

Appendix A: Ethical Statement \& Preregistration Information......................... p.1

Appendix B: Demographic \& Partisan Breakdown of the Sample..........................p.2

Appendix C: Text of Measures \& Response Options...................................... 3

Appendix D: Manipulation Check \& Balance Test Results................................p. 10

Appendix E: CDC Links Provided to Respondents..................................... 12 


\section{SUPPLEMENTAL APPENDIX A: ETHICAL STATEMENT \& PREREGISTRATION INFORMATION}

All studies obtained Institutional Review Board (IRB) approval from the researchers' respective universities prior to fielding each survey. Each survey lasted approximately 8 minutes and concluded by thanking and debriefing respondents about the general purpose of the study. Respondents participated voluntarily and were compensated for their participation in an ethical manner, and in a way consistent with existing research practice (e.g., see Berinsky, Huber and Lenz 2012). Respondents in the Lucid study were paid $\$ 1$ for their participation (approximately $97 \%$ of the U.S. federal minimum wage (equal to $\$ 7.25$ at the time of our studies).

\section{Preregistration Information}

This study was preregistered on the Open Science Framework (OSF) on September 21, 2021, at 8:12 GMT-0400, and prior to any data collection. We report no discrepancies between preregistered hypotheses and intended study design and the study presented in the main text of this

manuscript. To read the pre-registration documentation please follow this hyperlink: https://osf.io/yucx9/?view_only=44058172c9fc475cb6b3c20dee816608. [Anonymized version provided for the purposes of peer review]. 


\section{SUPPLEMENTAL APPENDIX B: \\ DEMOGRAPHIC \& PARTISAN BREAKDOWN OF THE SAMPLE}

We recruited a total of 1,561 unique adult U.S. respondents from the Lucid Theorem participant marketplace from September 22-23, 2021. We analyzed the results for 477 Republican identifiers and leaners and 740 Democratic identifiers and leaners, resulting in a study $\mathrm{N}$ of 1,217 U.S. adults with a partisan affiliation. Among these partisans, the median age was 45 years, $49.4 \%$ were male, $52.6 \%$ had a college education or higher, $73.2 \%$ identified as white, and the median household income was between $\$ 40,000$ and $\$ 44,999.72 \%$ of respondents reported having already received at least one dose of the COVID-19 vaccine. 


\title{
SUPPLEMENTAL APPENDIX C: \\ TEXT OF MEASURES \& RESPONSE OPTIONS
}

Pre-Treatment Items

\section{Party Identification}

Generally speaking, do you consider yourself to be a(n):

\author{
Strong Democrat \\ Democrat \\ Independent, but Leaning Democratic \\ Independent \\ Independent, but Leaning Republican \\ Republican \\ Strong Republican
}

\section{Covid Vaccine Self-Report}

Have you received at least one dose of the COVID-19 vaccine?

Yes

No

\section{Covid Vaccine Detailed Self-Report}

[IF Have you received at least one dose of the COVID-19 vaccine? = Yes]:

Which vaccine did you receive?

Pfizer-BioNTech

Johnson \& Johnson / Janssen

Moderna

I don't know 
Treatment Text: EC Message

[If Partisanship = Strong Democrat, Democrat, or Independent, but leaning Democrat]:

\section{A Message from the Democratic National Committee}

The Democratic National Committee (DNC) often serves as the national voice of the Democratic party. The Democratic National Committee recently released the following statement regarding COVID-19 and vaccines:

"We strongly agree with President Biden and members of his administration, who have gone on record by encouraging all Americans to get the COVID-19 vaccine as soon as possible to stop the spread of the virus. Thank you, Joe Biden, for your leadership on this issue."

[If Partisanship = Strong Republican, Republican, or Independent, but leaning Republican]:

\section{A Message from the Republican National Committee}

The Democratic National Committee (RNC) often serves as the national voice of the Republican party. The Republican National Committee recently released the following statement regarding COVID-19 and vaccines:

"We strongly agree with former President Trump and members of his administration, who have gone on record by encouraging all Americans to get the COVID-19 vaccine as soon as possible to stop the spread of the virus. Thank you, President Trump, for your leadership on this issue." 
Treatment Text: Shot to Win

[If Partisanship = Strong Democrat, Democrat, or Independent, but leaning Democrat]:

A Message from the Democratic National Committee: Vaccines Will Help Our Party Win!

The Democratic National Committee (DNC) often serves as the national voice of the Democratic party. The Democratic National Committee recently released the following statement regarding COVID-19 and vaccines:

"We strongly agree with President Biden and members of his administration, who have gone on record by encouraging all Americans to get the COVID-19 vaccine as soon as possible to stop the spread of the virus. Thank you, Joe Biden, for your leadership on this issue."

"Based on our own research, if you don't get vaccinated between now and the next election, you have a much higher risk of getting very sick. This means you might not be able to participate in the next election to help our party win."

"Please make sure you and your friends/relatives get vaccinated so you can help us defeat the Republicans in the next election. The stakes are very high: If we don't get vaccinated against COVID-19, Republicans might take back Congress in the 2022 midterm elections. They might possibly even win back the White House in 2024."

"We just can't take that risk. The COVID-19 vaccine is how we can keep Democrats healthy and strong. So let's get vaccinated, let's get protected, and let's get out and WIN in 2022 and 2024!" 
[If Partisanship = Strong Republican, Republican, or Independent, but leaning Republican]:

A Message from the Republican National Committee: Vaccines Will Help Our Party Win!

The Republican National Committee (RNC) often serves as the national voice of the Republican party. The Republican National Committee recently released the following statement regarding COVID-19 and vaccines:

"We strongly agree with former President Trump and members of his administration, who have gone on record by encouraging all Americans to get the COVID-19 vaccine as soon as possible to stop the spread of the virus. Thank you, Donald Trump, for your leadership on this issue."

"Based on our own research, if you don't get vaccinated between now and the next election, you have a much higher risk of getting very sick. This means you might not be able to participate in the next election to help our party win."

"Please make sure you and your friends/relatives get vaccinated so you can help us defeat the Democrats in the next election. The stakes are very high: If we don't get vaccinated against COVID-19, Democrats might keep their hold on Congress in the 2022 midterm elections. They might possibly even keep the White House in 2024."

"We just can't take that risk. The COVID-19 vaccine is how we can keep Republicans healthy and strong. So let's get vaccinated, let's get protected, and let's get out and WIN in 2022 and 2024!"

\section{Post-Treatment Measures}

Intention to Vaccinate: Vaccine

[If Have you received at least one dose of the COVID-19 vaccine? = No]:

If you had an opportunity to receive the COVID-19 vaccine in the very near future, how likely are you to accept the offer?

Extremely unlikely

Somewhat unlikely

Neither likely nor unlikely

Somewhat likely

Extremely likely

Intention to Vaccinate: Booster Shot

[If Have you received at least one dose of the COVID-19 vaccine? = Yes]

A "booster" is a vaccine dose that helps improve your body's ability to fight infection. 
If you had an opportunity to receive a COVID-19 vaccine booster in the very near future, how likely are you to accept the offer?

Extremely unlikely

Somewhat unlikely

Neither likely nor unlikely

Somewhat likely

Extremely likely

\section{Intention to Vaccinate: Resistance Detail}

[If Have you received at least one dose of the COVID-19 vaccine? = No]:

Please tell us whether you agree with any of the following statements.

Check all that apply.

I want to get the COVID-19 vaccine, but I haven't been able to yet

I haven't gotten the vaccine because I worry about potential side effects

I don't think the vaccine is necessary, because COVID-19 is not very dangerous

I am skeptical of the government agencies who are promoting vaccination

I don't trust vaccines of any kind

\section{Willingness to Promote Vaccination: Encourage Family Members}

If you had a family member who was unsure whether or not to get vaccinated with the COVID19 vaccine, how likely would you be to encourage them to get the vaccine?

Extremely unlikely

Somewhat unlikely

Neither likely nor unlikely $b$

Somewhat likely

Extremely likely

\section{Requests for CDC Vaccine Information: Seek Vaccine Facts}

If you'd like, at the end of the survey, we can provide you with an online link to accurate, established facts regarding COVID-19 and vaccines. Would you like us to include this information at the end of the survey?

No

Yes 


\section{Requests for CDC Vaccine Information: Seek Vaccine Location}

If you'd like, at the end of the survey, we can provide you with an online link to information about where you can get vaccinated in your area. Would you like us to include this information at the end of the survey?

No

Yes

\section{Manipulation Checks}

\section{Lose 2022 Election Manipulation Check}

If other voters in your political party continue to refuse to get the COVID-19 vaccine, how likely is it that your party will lose the 2022 Congressional elections?

\section{Extremely unlikely}

Somewhat unlikely

Neither likely nor unlikely

Somewhat likely

Extremely likely

\section{Lose 2024 Election Manipulation Check}

If other voters in your political party continue to refuse to get the COVID-19 vaccine, how likely is it that your party will lose the 2024 Presidential election?

Extremely unlikely

Somewhat unlikely

Neither likely nor unlikely

Somewhat likely

Extremely likely

\section{Consequences Manipulation Check: Republicans [If PID is Republican]:}

Recent research from the Republican National Committee suggests that unvaccinated people who get sick from COVID-19 might not be able to... (choose all that apply)

Get out and vote in upcoming elections

Attend public meetings

Follow political news about COVID-19

Answer public opinion polls

Write letters to their representatives in Congress 


\section{Consequences Manipulation Check: Democrats}

[If PID is Democratic]: Recent research from the Democratic National Committee suggests that unvaccinated people who get sick from COVID-19 might not be able to... (choose all that apply):

Get out and vote in upcoming elections

Attend public meetings

Follow political news about COVID-19

Answer public opinion polls

Write letters to their representatives in Congress 


\section{SUPPLEMENTAL APPENDIX D: \\ MANIPULATION CHECK \& BALANCE TEST RESULTS}

Manipulation checks indicated that the $S T W$ treatment condition was successfully received by treated respondents. Among all respondents, compared to Control, respondents in STW reported an increase in the belief that their party would lose the 2022 election (if co-partisans refuse to vaccinate) of 5.9 percentage points $(p<0.01)$. Regarding the same possibility in the 2024 presidential election, respondents in $S T W$ reported a 6.7 percentage point increase relative to Control $(p<0.01)$. For Republicans alone, these differences were $8.0(p<0.05)$ and $10.3(p<$ 0.01) percentage points, respectively.

Further manipulation checks specifically tested whether respondents treated in the STW condition, relative to the Control condition, specifically invoked the inability to vote as a condition of not getting vaccinated (among other possibilities, including attending public meetings, following news about COVID-19, contacting members of Congress, and answering polls). Relative to the Control, $S T W$ respondents were roughly 6.5 percentage points more likely to specifically mention voting among these choices $(p<0.10)$. Results for Republicans alone were similar but did not attain conventional levels of statistical significance (a difference of 7.2 relative to Control; $p=0.19)$. In total, $62 \%$ of Republicans in the $S T W$ condition correctly selected that unvaccinated people might not "be able to get out and vote in upcoming elections," indicating satisfactory attentiveness.

Results of Balance Tests

We conducted balance tests to ensure that random assignment was successful. Specifically, we employed a multinomial logistic regression model, which regressed the trichotomous indicator 
of experimental condition (Control, EC, or $S T W$ ) onto ideological self-placement (ranging from "very liberal" to "very conservative"), household income, education level, age, racial identification (nonwhite vs. white), gender identification, and region of residence (Northeast, Midwest, South, or West).

For the sample as a whole, this model yielded a non-significant $\chi^{2}$ statistic $(p=.498)$, with no variables being significantly predictive of treatment assignment at the $p<.05$ level. For Republican respondents only, this model was again non-significant $(p=.392)$, though there was some evidence that respondents located in the Midwest and South were slightly more likely to be in the $S T W$ condition than in the Control condition. However, when the main results were reanalyzed with statistical controls for regional location, the estimated effect sizes did not meaningfully change compared to those reported in the manuscript (in fact, treatment effect estimates tended to be slightly larger when controlling for regional location). 


\section{SUPPLEMENTAL APPENDIX E: CDC LINKS PROVIDED TO RESPONDENTS}

Respondents who answered "Yes" to the item Requests for CDC Vaccine Information: Seek Vaccine Facts were provided with a final survey block which included a link to the requested information. Similarly, respondents who answered "Yes" to the item Requests for CDC Vaccine Information: Seek Vaccine Location were provided with information about where to get vaccinated. Those who answered "Yes" to both items saw a message with the following contents:

You indicated an interest in receiving factual information about the COVID-19 vaccine. Please click on this link to view an article, entitled "Myths and Facts about COVID-19 Vaccines," by the non-partisan Centers for Disease Control and Prevention.

You also indicated an interest in receiving information about where to obtain a COVID-19 vaccine.

Please click on this link to be taken to the non-partisan Centers for Disease Control and Prevention, which will provide you with information about how to find a vaccination location near vou in a separate window.

The first link took respondents to the following website:

https://www.cdc.gov/coronavirus/2019-ncov/vaccines/facts.html. This site, entitled "Myths and Facts about COVID-19 Vaccines," provides information about how vaccines work, how vaccination protects communities, and dispels common misinformation about topics such as viral shedding, microchips, and magnetism.

The second link, https:/www.cdc.gov/coronavirus/2019-ncov/vaccines/How-Do-I-Get-a-COVID-19Vaccine.html?s_cid=10503:how\%20to\%20get\%20covid\%20vaccine:sem.ga:p:RG:GM:gen:PTN:FY21 , took survey respondents to a CDC site which provided them with three methods to find out how 
to get vaccinated in their local area. This included a further link to http://vaccines.gov, a phone number which receives users' ZIP codes via text and provides nearby vaccination locations, and other suggestions for local and regional resources. 